\title{
Nano Analyses of Adsorbed Film onto Carbon Steel
}

\author{
T. Kasilingam, ${ }^{a,{ }^{*}}$ C. Thangavelu, ${ }^{b, *}$ V. Palanivel ${ }^{a}$ \\ ${ }^{a} P G \&$ Research Department of Chemistry, Periyar E. V. R. College (Autonomous), \\ Tiruchirappalli, Tamilnadu, India \\ ${ }^{b}$ Department of Chemistry, Govt. Arts College for Women, Nilakkottai, Dindugul, Tamilnadu, \\ India
}

Received 30 July 2014; accepted 23 August 2014

\begin{abstract}
The inhibition performance of a non-oxidising surfactant, namely cetyl trimethyl ammonium bromide (CTAB), and its co-adsorption behaviour with zinc ion on carbon steel in well water was studied by potentiodynamic polarization, electrochemical impedance spectroscopy (EIS), weight loss, as well as atomic force microscopy (AFM) and scanning electron microscopy. Results indicated that the formulation acted as an anodic inhibitor. Adsorption of the used inhibitor led to a reduction in the double layer capacitance and an increase in the charge transfer resistance. A synergistic effect was also observed for the studied inhibitor with $\mathrm{Zn}^{2+}$ in weight loss measurements and electrochemical studies.
\end{abstract}

Keywords: Weight loss, Electrochemical studies, AFM, SEM.

\section{Introduction}

A district heating system provides high temperature for the inhabitants of large cities [1]. There are many advantages from a district heating system, including increased energy and performance efficiencies achieved through implementing advanced equipment and maintaining them professionally, reduced life cycle costs, and augmented control over environmental impacts [2,3]. A district heating system has three main elements: the heat sources, the distribution system and the customer interfaces [4]. District heating system and corrosion of the pipelines are relevant issues. The customer interface uses well water, therefore quite extensive corrosion of steel and iron occurs, even after lime treatment [5]. There will be numerous problems such as corrosion of pipelines, space heating networks, and other equipment of the systems. All these disadvantages dramatically reduce the

\footnotetext{
*Corresponding author. E-mail address: thavankasi@gmail.com; drkctv@gmail.com
} 
service time of the whole district heating system [6]. Many methods such as coating [7], phosphating [8], anodic or cathodic controls [9] and use of inhibitors [10] are adopted to minimize the corrosion problems. Among them only the use of inhibitors is convenient and economic [11-13].

Surfactant corrosion inhibitors have many advantages such as high inhibition efficiency, low price, low toxicity, and simple production. Surfactants are molecules composed of a polar hydrophilic group, the "head", attached to a non-polar hydrophobic group, the "tail". Generally, in aqueous solution the inhibitory action of surfactant molecules may also be due to physical (electrostatic) adsorption or chemisorption onto the metallic surface, depending on the charge of the solid surface and the free energy change of transferring a hydrocarbon chain from water to the solid surface.

The adsorption of a surfactant markedly changes the corrosion resisting property of a metal. For these reasons, studying the relation between adsorption and corrosion inhibition is significantly important [14-23]. Somewhat recently, the corresponding research has also demonstrated that quaternary ammonium salt surfactants are efficient corrosion inhibitors for iron and steel [24-29].

This article investigates the inhibition of corrosion of carbon steel in well water using CTAB and $\mathrm{Zn}^{2+}$ by using different techniques. The effectiveness of the formulation is explained on the basis of electrochemical parameters obtained from Tafel and Nyquist curves. In the present work the use of Scanning Electron Microscopy has been made to obtain a clear understanding of the protective film onto carbon steel surface without and with an inhibitor formulation.

\section{Experimental details \\ Materials}

The composition of carbon steel used for corrosion inhibition studies was (Wt $\%$ ): $0.026 \% \mathrm{~S}, 0.06 \% \mathrm{P}, 0.4 \% \mathrm{Mn}, 0.1 \% \mathrm{C}$ and balance being Fe. The specimens of size $1.0 \mathrm{~cm} \times 4.0 \mathrm{~cm} \times 0.2 \mathrm{~cm}$ were press cut from the carbon steel sheet, were machined and abraded with a series of emery papers. This was followed by rinsing in acetone and bidistilled water and finally dried in air. Before any experiment, the substrates were treated as described and freshly used with no further storage. The inhibitors CTAB, molecular mass $364.45 \mathrm{~g} \mathrm{~mol}^{-1}, \mathrm{Zn}^{2+}$ ions were used as received.

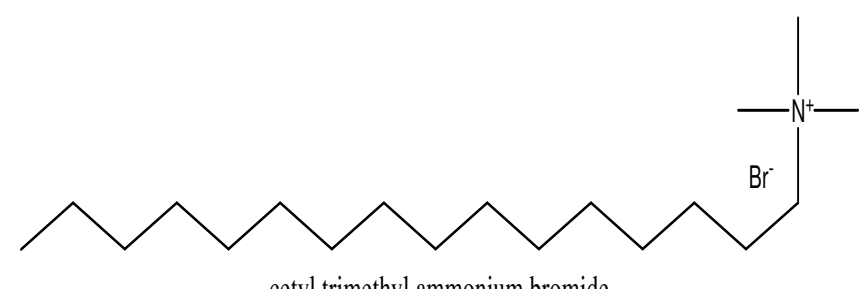

Figure 1. Molecular structure of CTAB.

A stock solution of $1000 \mathrm{ppm}$ of CTAB was prepared with bidistilled water and the desired concentration was obtained by appropriate dilution. The concentration of CTAB used for the study ranges from 10 to $150 \mathrm{ppm}$. All 
solutions were prepared using well water (Tiruchirappalli, Tamil Nadu, India). The study was carried out at room temperature. The molecular structure of CTAB is given in Fig. 1. The chosen environmental well water and its physicochemical parameters are given in Table 1.

Table 1. Physico-chemical parameters of well water.

\begin{tabular}{cc}
\hline Parameters & Values \\
\hline $\mathrm{pH}$ & 8.0 \\
TDS & $1092 \mathrm{ppm}$ \\
Chloride & $220 \mathrm{ppm}$ \\
Alkalinity & $300 \mathrm{ppm}$ \\
Total Hardness & $450 \mathrm{ppm}$ \\
Conductivity & $1747 \mu \mathrm{mhos} / \mathrm{cm}$
\end{tabular}

\section{Weight - loss measurements}

The freshly prepared carbon steel specimens were suspended in $150 \mathrm{~mL}$ beakers containing $100 \mathrm{~mL}$ of test solution maintained at room temperature with the aid of glass rods and hooks. The weight loss taken was the difference between the weight at a given time and the original weight of the specimens. The measurements were carried out for the uninhibited solution and the solution containing $\mathrm{CTAB}$ and $\mathrm{CTAB}-\mathrm{Zn}^{2+}$ mixture. Weight loss experiments were performed for the duration of seven days. The specimens were immersed in triplicate and the average corrosion rate was calculated.

These uncertainties or RSD for three replicate measurements were less than $5 \%$. The corrosion rates $\left(C_{R}\right)$ were determined using the equation:

$$
\text { Corrosion Rate }\left(\frac{m m}{y}\right)=\frac{87.6 \times W}{\text { AT D }}
$$

where $\mathrm{W}=$ corrosion weight loss of carbon steel $(\mathrm{mg}) ; \mathrm{A}=$ area of the coupon $\left(\mathrm{cm}^{2}\right) ; \mathrm{T}=$ exposure time $(\mathrm{h}) ; \mathrm{D}=$ density of the carbon steel $\left(\mathrm{g} \mathrm{cm}^{-3}\right)$.

The inhibition efficiency (IE) of CTAB and $\mathrm{Zn}^{2+}$ mixture was calculated by using the following equation:

$$
\% I E=\frac{C R o-C R i}{C R o}
$$

where $\mathrm{CRo}=$ corrosion rate of carbon steel in the absence of the inhibitor; $\mathrm{CRi}=$ corrosion rate of carbon steel in the presence of the inhibitor.

\section{Surface analysis by FTIR spectroscopy}

After the immersion period of one day in various environments, the specimens were taken out of the test solution and dried. The film formed on the surface was scratched carefully and it was thoroughly mixed so as to make it uniform throughout. FTIR spectrum of the powder (KBr Pellets) was recorded using a Perkin-elmer-1600 FTIR spectrophotometer with resolving power of $4 \mathrm{~cm}^{-1}$. 


\section{Electrochemical studies}

Both the potentiodynamic polarization studies and electrochemical impedance spectroscopic (EIS) studies were carried out using the electrochemical workstation model CHI- 760d and the experimental data were analysed by using the electrochemical software (Version: 12.22.0.0).

The measurements were conducted in a conventional three electrode cylindrical glass cell with a platinum electrode as auxiliary electrode and a saturated calomel electrode as reference electrode.

The working electrode was carbon steel embedded in epoxy resin of polytetrafluoroethylene so that the flat surface of $1 \mathrm{~cm}^{2}$ was the only surface exposed to the electrolyte. The three electrodes set up was immersed in a control solution of volume $100 \mathrm{~mL}$ both in the absence and presence of the inhibitors formulations and allowed to attain a stable open circuit potential (OCP). The $\mathrm{pH}$ values of the solution were adjusted to 7.0 and the solutions were unstirred during the experiments.

Polarization curves were recorded in the potential range of -750 to $-150 \mathrm{mV}$ with a resolution of $2 \mathrm{mV}$. The curves were recorded in the dynamic scan mode with a scan rate of $2 \mathrm{mV} \mathrm{s}^{-1}$ in the current range of $-20 \mathrm{~mA}$ to $+20 \mathrm{~mA}$. The Ohmic drop compensation has been made during the studies. The corrosion potential $\left(\mathrm{E}_{\mathrm{corr}}\right)$, corrosion current $\left(\mathrm{I}_{\text {corr }}\right)$, anodic Tafel slope $\left(\beta_{\mathrm{a}}\right)$ and cathodic Tafel slope $\left(\beta_{\mathrm{c}}\right)$ were obtained by extrapolation of anodic and cathodic regions of the Tafel plots. The inhibition efficiency $\left(\mathrm{IE}_{\mathrm{p}}\right.$ ) values were calculated from the $\mathrm{I}_{\text {corr }}$ values using the equation

$$
\operatorname{IE}_{\mathrm{p}}(\%)=\left[1-\left(\mathrm{I}_{\text {corr }} / \mathrm{I}_{\text {corr }}\right)\right] \times 100
$$

where $I_{\text {corr }}$ and $I_{\text {corr }}$ are the corrosion current densities in case of control and inhibited solutions, respectively.

Electrochemical impedance spectra in the form of Nyquist plots were recorded at OCP in the frequency range from $60 \mathrm{KHz}$ to $10 \mathrm{MHz}$ with 4 to 10 steps per decade. A sine wave, with $10 \mathrm{mV}$ amplitude, was used to perturb the system. The impedance parameters viz., charge transfer resistance $\left(R_{c t}\right)$, double layer capacitance $\left(\mathrm{C}_{\mathrm{dl}}\right)$ were obtained from the Nyquist plots. The inhibition efficiencies $\left(\mathrm{IE}_{\mathrm{i}}\right)$ were calculated using the equation,

$$
\mathrm{IE}_{\mathrm{i}}(\%)=100\left[1-\mathrm{R}_{\mathrm{ct}} / \mathrm{R}_{\mathrm{ct}}^{\prime}\right]
$$

where $R_{c t}$ and $R_{c t}^{\prime}$ are the charge transfer resistance values in the absence and presence of the inhibitor, respectively.

\section{Scanning Electron Microscopy}

The surface morphology of the corroded steel sample surface in the presence and absence of the inhibitors was studied using SEM (Model: TESCAN vega3 USA). To study the surface morphology of carbon steel, polished specimens prior to initiation of any corrosion reaction, were examined in optical microscope to find out any surface defect, such as prior noticeable irregularities like cracks, etc. Only those specimens, which had a smooth pit-free surface, were subjected to immersion. The specimens were immersed for $24 \mathrm{~h}$ at $30^{\circ} \mathrm{C}$. After completion of 
the tests the specimens were thoroughly washed with bidistilled water and dried and then subjected to SEM examination.

\section{Atomic Force Microscopy (AFM)}

Atomic force microscopy is a powerful method for the gathering of roughness statistics from a variety of surfaces. This exciting new technique allows the surface to be imaged at higher resolutions and accuracies than ever before. The protective films are examined for a scanned area. AFM is becoming an accepted technique of roughness investigation [30-33].

All the AFM images were recorded on a Pico SPM2100 AFM instrument operating in contact mode in air. The scan size of all the AFM images are $40 \mu \mathrm{m}$ $\times 40 \mu \mathrm{m}$ and $5 \mu \mathrm{m} \times 5 \mu \mathrm{m}$ areas at a scan rate of $0.20\left(\mathrm{H}_{\mathrm{z}}\right)$ lines per second.

\section{Results and discussion \\ Weight-loss measurements}

Table 2 shows corrosion rates, inhibition efficiencies and synergism parameters of the carbon steel determined by the weight loss tests in well water without and with an inhibitor, and in $25 \mathrm{ppm} \mathrm{Zn}^{2+}$ inhibitor + CTAB different concentrations during seven days at $303 \mathrm{~K}$.

It can be observed that the addition of the inhibitor suppressed effectively the carbon steel corrosion in well water. The inhibition efficiency increased with increasing concentrations of the inhibitor and also increases the synergism parameter and then reached the maximum value when the inhibitor concentration was 150 ppm CTAB, indicating that the inhibition effect depends on the amount of the inhibitor. This trend can be attributed to an increase in the adsorption amount of inhibitor onto carbon steel surface with increasing inhibitor concentrations, separating the carbon steel surface from the corrosion medium and retarding corrosion via forming an inhibitor adsorption film.

Besides, it can be seen from Table 2 that after addition of $\mathrm{Zn}^{2+}$ ions into the well water with $150 \mathrm{ppm}$ CTAB, corrosion rates decreased significantly in comparison with singular inhibitor in well water, as well as the inhibition

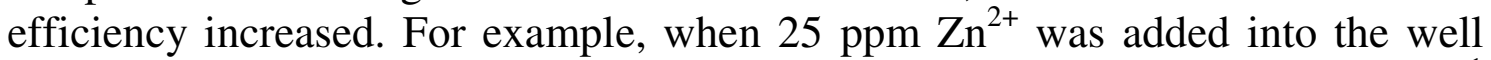
water containing $150 \mathrm{ppm}$ CTAB, the corrosion rate reduced from $141.1 \mathrm{mmy}^{-1}$ to $17.5 \mathrm{mmy}^{-1}$. Accordingly, the percentage of inhibition efficiency increased from $27 \%$ to $91 \%$. These results suggest that there is a synergistic effect between inhibitor molecules and $\mathrm{Zn}^{2+}$ ion synergism parameter $\left(\mathrm{S}_{\mathrm{I}}\right)[34,35]$ values shown in Table 2. This is defined as,

$$
\mathrm{S}_{\mathrm{I}}=\left(1-\mathrm{I}_{1+2}\right) /\left(1-\mathrm{I}_{1+2}\right)
$$

where $I_{1+2}=\left(I_{1}+I_{2}\right)-\left(I_{1 \times} I_{2}\right) ; I_{1}=$ surface coverage of inhibitors $(C T A B) ; I_{2}=$ surface coverage of inhibitors $\left(\mathrm{Zn}^{2+}\right) ; \mathrm{I}_{1+2}^{\prime}=$ combined surface coverage of inhibitors (CTAB) and $\left(\mathrm{Zn}^{2+}\right)$. 
Table 2. Calculated corrosion rates $\left(\mathrm{C}_{\mathrm{R}}\right)$, inhibition efficiency (IE) and synergism parameter $\left(\mathrm{S}_{\mathrm{I}}\right)$ from the weight loss measurements for carbon steel in well water without and with various concentrations of the inhibitor, during seven days at $303 \mathrm{~K}$.

\begin{tabular}{|c|c|c|c|c|c|}
\hline $\begin{array}{c}\text { Conc. of } \mathbf{Z n}^{2+} \\
(\mathbf{p p m})\end{array}$ & $\begin{array}{c}\text { Conc. of CTAB } \\
(\mathbf{p p m})\end{array}$ & $\mathbf{C}_{\mathbf{R}}\left(\mathbf{m m y}^{-\mathbf{1}}\right)$ & $\boldsymbol{\%} \mathbf{I E}$ & $\begin{array}{c}\text { Surface } \\
\text { coverage }(\boldsymbol{\theta})\end{array}$ & $\begin{array}{c}\text { Synergism } \\
\left(\mathbf{S}_{\mathbf{I}}\right)\end{array}$ \\
\hline Blank & - & 194.4 & - & - & - \\
\hline 25 & - & 155.5 & 20 & 0.20 & - \\
\hline- & 10 & 188.6 & 3 & 0.03 & - \\
\hline- & 25 & 178.9 & 8 & 0.08 & - \\
\hline- & 50 & 171.1 & 12 & 0.12 & - \\
\hline- & 75 & 163.3 & 16 & 0.16 & - \\
\hline- & 100 & 155.5 & 20 & 0.20 & - \\
\hline- & 125 & 149.7 & 23 & 0.23 & - \\
\hline- & 150 & 141.1 & 27 & 0.27 & - \\
\hline 25 & 10 & 143.9 & 26 & 0.26 & 1.0486 \\
\hline 25 & 25 & 130.3 & 33 & 0.33 & 1.0985 \\
\hline 25 & 50 & 114.7 & 41 & 0.41 & 1.1932 \\
\hline 25 & 75 & 93.3 & 52 & 0.52 & 1.4000 \\
\hline 25 & 100 & 62.2 & 68 & 0.68 & 2.0000 \\
\hline 25 & 125 & 44.7 & 77 & 0.77 & 2.6782 \\
\hline 25 & 150 & 17.5 & 91 & 0.91 & 6.4889 \\
\hline
\end{tabular}

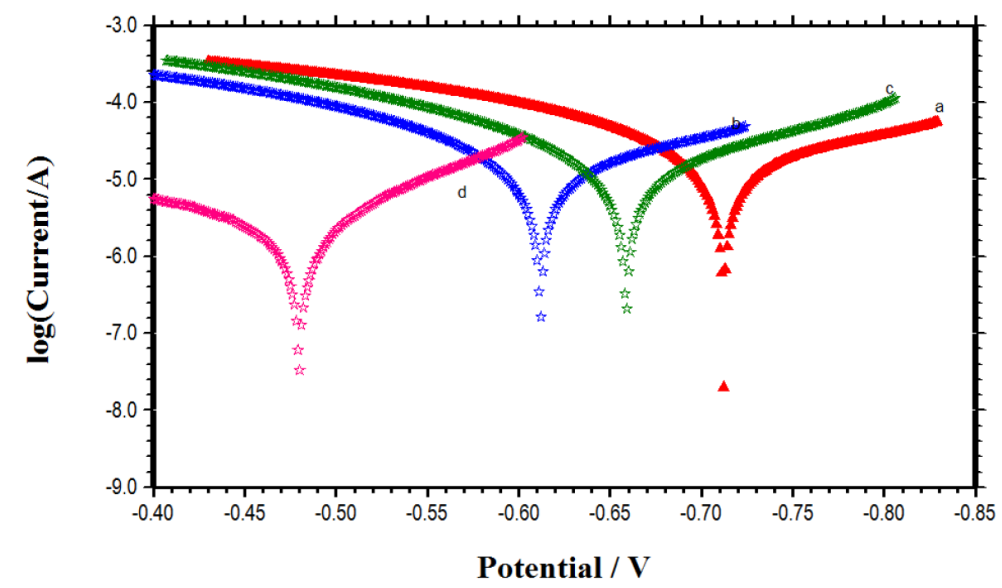

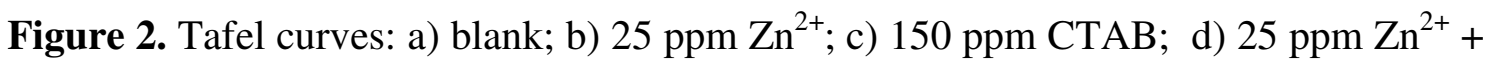
150 ppm CTAB.

\section{Polarization study}

Fig. 2 shows the Tafel curves of carbon steel in well water without and with an inhibitor, respectively. The Tafel curve for the $\left(\mathrm{CTAB}+\mathrm{Zn}^{2+}\right)$ inhibitor formulation indicates a shift of the corrosion potential toward a more positive value potential compared toward with the blank assess (from $-712 \mathrm{mV}$ to -480 $\mathrm{mV}$ ). This corrosion potential shift was a result of the anodic inhibition effect of the inhibitor formulation. The anode Tafel curve obtained with the inhibitor indicates a greater trend toward passivity than without the inhibitor. Also, the cathodic zone showed the limiting current decreased for oxygen reduction. However, according to the corrosion potential the inhibitor formulation tended toward the anode inhibition.

From the Tafel curves, the corrosion current density $\left(i_{\text {corr }}\right)$ was determined by the Tafel extrapolation method; they were $\left(2.676 \mathrm{Acm}^{-2}\right)$ (without) and $0.254 \mathrm{Acm}^{-2}$ (with), respectively. The corrosion current density in well water decreased 
gradually with the inhibitor. The inhibition efficiency $\left(\mathrm{IE}_{\mathrm{pol}} \%\right)$ of the inhibitor formulation for the corrosion of carbon steel was calculated using $i_{\text {corr }}$ [36].

The synergism parameters $\left(\mathrm{S}_{\mathrm{I}}\right)$ of the inhibitor formulation were calculated using the equation given below:

$$
\mathrm{S}_{\mathrm{I}}=\left(1-\mathrm{I}_{1+2} / 1-\mathrm{I}_{1+2}\right)
$$

where $I_{1+2}=\left(I_{1}+I_{2}\right)-\left(I_{1 \times} I_{2}\right) ; I_{1}=$ surface coverage of inhibitors $(C T A B) ; I_{2}=$ surface coverage of inhibitors $\left(\mathrm{Zn}^{2+}\right) ; \mathrm{I}_{1+2}=$ combined surface coverage of inhibitors (CTAB) and $\left(\mathrm{Zn}^{2+}\right)$.

Table 3. Calculated corrosion inhibition efficiency (IE) from the polarization study for carbon steel in well water without and with the inhibitor.

\begin{tabular}{|c|c|c|c|c|c|c|}
\hline \multicolumn{2}{|c|}{ Concentration (ppm) } & \multicolumn{4}{|c|}{ Tafel parameters } & \multirow{2}{*}{$\begin{array}{l}\mathbf{I E}_{\mathrm{p}} \\
(\%)\end{array}$} \\
\hline CTAB & $\mathrm{Zn}^{2+}$ & $\begin{array}{c}E_{\text {corr }} \\
\text { mV vs. SCE }\end{array}$ & $I_{\text {corr }} \mathrm{A} / \mathbf{c m}^{2} \times 10^{-5}$ & $\beta_{\mathrm{a}} \mathrm{mV} /$ decade & $\beta_{\mathrm{c}} \mathrm{mV} /$ decade & \\
\hline Blank & - & -712 & 2.676 & 170.3 & 198.4 & - \\
\hline- & 25 & -612 & 2.158 & 154.7 & 180.5 & 19.35 \\
\hline 150 & - & -655 & 1.988 & 149.7 & 156.9 & 25.71 \\
\hline 150 & 25 & -480 & 0.254 & 236.9 & 106.0 & 90.50 \\
\hline
\end{tabular}

Table 4. Calculated Synergism parameter $\left(\mathrm{S}_{\mathrm{I}}\right)$ from the polarization study for carbon steel in well water.

\begin{tabular}{|c|c|c|c|c|c|}
\hline $\begin{array}{c}\text { Conc. of } \\
\mathbf{Z n}^{2+}(\mathbf{p p m})\end{array}$ & $\begin{array}{c}\text { Conc. of } \\
\mathbf{C T A B}(\mathbf{p p m})\end{array}$ & $\begin{array}{c}\mathbf{I}_{\mathbf{c o r r}}, \mathbf{A . c m}^{-\mathbf{2}}, \mathbf{\times} \\
\mathbf{1 0}^{-5}\end{array}$ & $\mathbf{I E}_{\mathbf{p o l}}, \boldsymbol{\%}$ & $\begin{array}{c}\text { Surface } \\
\text { coverage }(\boldsymbol{\theta})\end{array}$ & $\begin{array}{c}\text { Synergism } \\
\left(\mathbf{S}_{\mathbf{I}}\right)\end{array}$ \\
\hline Blank & - & 2.676 & - & - & - \\
\hline 25 & - & 2.158 & 19.35 & 0.1935 & - \\
\hline- & 150 & 1.988 & 25.71 & 0.2771 & - \\
\hline 25 & 150 & 0.254 & 90.50 & 0.9050 & 6.3063 \\
\hline
\end{tabular}

Table 3 and Table 4 show the calculated results of inhibition efficiency and synergism results corroborating the results of the weight loss measurement and electrochemical impedance studies.

\section{AC impedance}

Fig. 3 shows the Nyquist plots for carbon steel in well water with and without the inhibitor of OCP. It can be observed that the impedance reaction of the electrode was significantly changed after the addition of co-adsorption of the inhibitor in the blank solution. In comparison with the blank solution, in the presence of the inhibitor, the diameters of the semi-circles in Nyquist plots increased with addition of co-adsorption inhibitor.

These results indicate that the impedance of the carbon steel electrode increased with addition of co-adsorption of the inhibitor, consequently resulting in an increase in inhibition effect, and that the carbon steel corrosion was effectively retarded due to the formation of a protective film onto the metal surface. In 
addition, the impedance spectra did not present semi circles; this phenomenon can be attributed to the frequency dispersion [37-38].

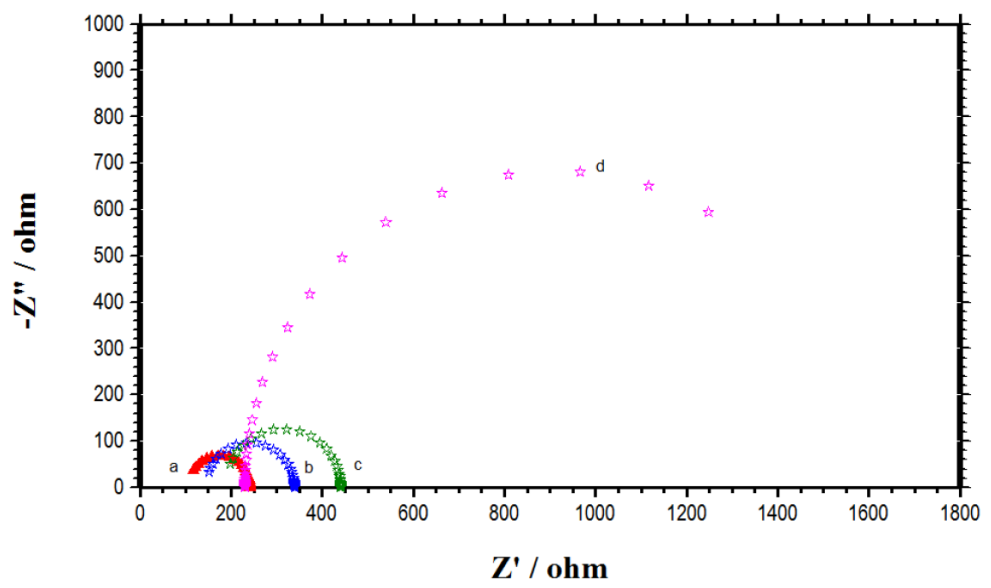

Figure 3. Nyquist plots: a) Blank; b) $25 \mathrm{ppm} \mathrm{Zn}^{2+}$; c) $150 \mathrm{ppm} \mathrm{CTAB}$; d) $25 \mathrm{ppm} \mathrm{Zn^{2+ }}$ +150 ppm CTAB.

It is also evident that the Nyquist plots are composed of two slightly depressed capacitive loops: the one at the high frequencies can be attributed to the charge transfer resistance $\left(\mathrm{R}_{\mathrm{ct}}\right)$, and to the double layer capacitance $\left(\mathrm{C}_{\mathrm{dl}}\right)$. The fitted electrochemical parameters are listed in Tables 5 and 6. It is apparent from these tables that by increasing addition of co-adsorption of the inhibitor, the $\mathrm{C}_{\mathrm{dl}}$ value tended to decrease, whereas the $\mathrm{R}_{\mathrm{ct}}$ value increased. The significant decreased in the capacitance values can be ascribed to a decrease in the dielectric constant or an increase in the double electric layer thickness due to the adsorption of the inhibitor molecule onto the carbon steel surface [39]. The results as obtained by electrochemical impedance studies are consistent with the results of the polarization study and weight loss measurements.

Table 5. Calculated corrosion inhibition efficiency (IE) from the electrochemical impedance study for carbon steel in well water without and with the inhibitor.

\begin{tabular}{|c|c|c|c|c|}
\hline \multicolumn{2}{|c|}{ Concentration (ppm) } & \multirow{2}{*}{$\begin{array}{l}\text { Charge Transfer } \\
\text { Resistance } \mathbf{R}_{\mathrm{ct}}(\boldsymbol{\Omega})\end{array}$} & \multirow{2}{*}{$\begin{array}{l}\text { Double layer capacitance } \\
\text { Cdl CPE }\left(\mu \mathrm{F} / \mathrm{cm}^{2}\right)\end{array}$} & \multirow[b]{2}{*}{ I.E (\%) } \\
\hline CTAB & $\mathbf{Z n}^{2+}$ & & & \\
\hline Blank & - & 135.10 & 17.290 & - \\
\hline- & 25 & 168.13 & 10.580 & 19.64 \\
\hline 150 & 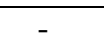 & 180.69 & 9.371 & 25.23 \\
\hline 150 & 25 & 1330.0 & 0.174 & 89.84 \\
\hline
\end{tabular}

Table 6. Calculated Synergism parameter $\left(S_{I}\right)$ from the electrochemical impedance study for carbon steel in well water.

\begin{tabular}{|c|c|c|c|c|c|}
\hline $\begin{array}{l}\text { Conc. of } \mathrm{Zn}^{2+} \\
(\mathbf{p p m})\end{array}$ & $\begin{array}{c}\text { Conc. of } \\
\text { CTAB (ppm) }\end{array}$ & $\mathbf{R}_{\mathrm{ct}} \mathrm{ohm} . \mathrm{cm}^{2}$ & $\% \mathrm{IE}_{\mathrm{imp}}$ & $\begin{array}{c}\text { Surface } \\
\text { coverage }(\theta)\end{array}$ & $\begin{array}{c}\text { Synergism } \\
\left(\mathbf{S}_{\mathbf{I}}\right)\end{array}$ \\
\hline Blank & - & 135.10 & - & - & - \\
\hline 25 & - & 168.13 & 19.64 & 0.1964 & - \\
\hline- & 150 & 180.69 & 25.23 & 0.2523 & - \\
\hline 25 & 150 & 1330.0 & 89.84 & 0.8984 & 5.9133 \\
\hline
\end{tabular}




\section{FTIR Spectra}

FTIR spectra were recorded to understand the interaction of inhibitor molecules with the metal surface [40-43]. The FTIR spectrum of pure CTAB is shown in Fig 4a. The $\mathrm{C}$-Br stretching frequency of the cetyl trimethyl ammonium bromide appears at $621 \mathrm{~cm}^{-1}$. The FTIR spectrum of the protective film formed onto the carbon steel surface after immersion in the solution containing $25 \mathrm{ppm} \mathrm{Zn}^{2+}$ and 150 ppm CTAB is shown in Fig 4b. The $\mathrm{C}-\mathrm{Br}$ stretching frequency of CTAB shifted from $621 \mathrm{~cm}^{-1}$ to $572 \mathrm{~cm}^{-1}$.

These results revealed that the $\mathrm{C}-\mathrm{Br}$ coordinated with $\mathrm{Fe}^{2+}$ on the anodic mode of the metal surface also resulted in the formation of $\mathrm{Fe}^{2+}-\mathrm{CTAB}$ complex. The peak appearing at $1382 \mathrm{~cm}^{-1}$ is due to $\mathrm{Zn}(\mathrm{OH})_{2}$ formed on the cathodic regions of the metal surface.

\section{Evidence of surface}

In order to further confirm the corrosion resistance ability of the formulation as a good corrosion inhibitor in well water, the surface morphology of carbon steel in well water without and with the inhibitor $\mathrm{Zn}^{2+}+\mathrm{CTAB}$ for one day exposure (Fig. 5) was investigated using scanning electron microscope (SEM).

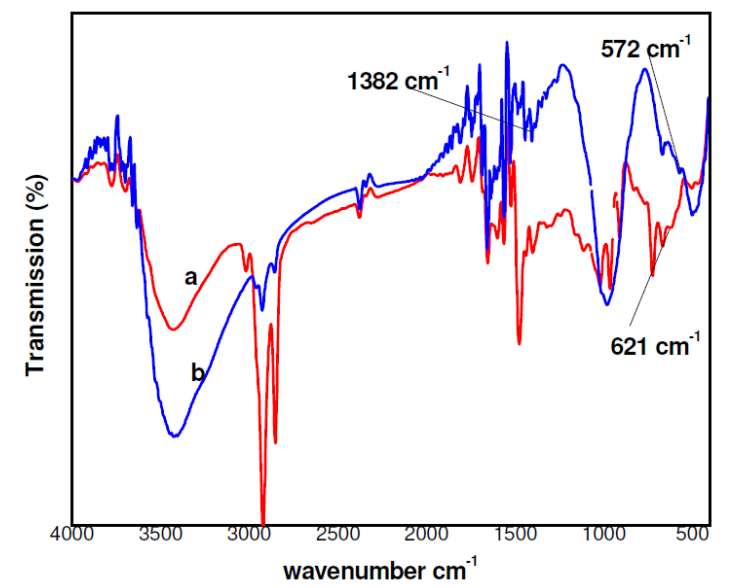

Figure 4. FTIR spectrum of a) pure sample of CTAB and b) scraped sample of CTAB $+\mathrm{Zn}^{2+}$.

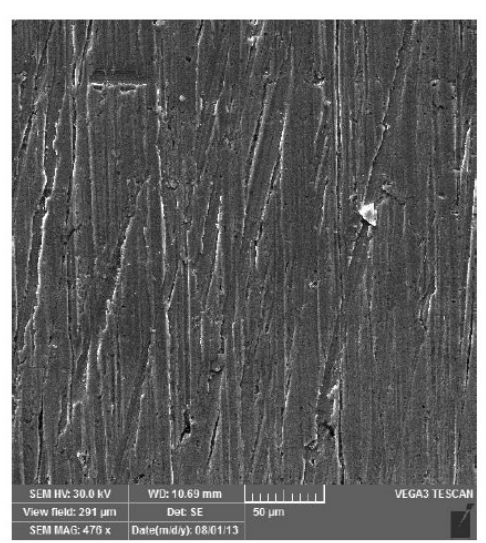

Figure 5a: polished metal

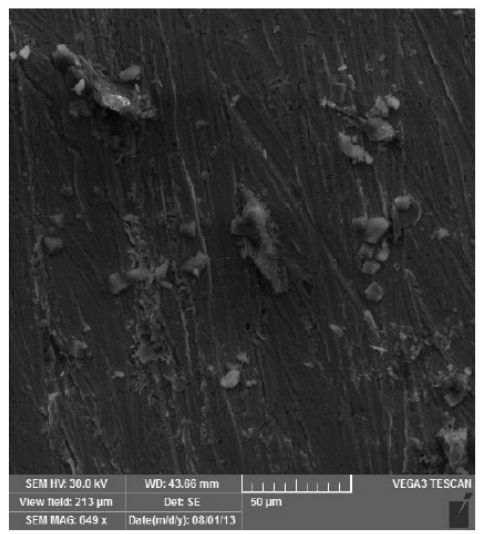

Figure 5b: without inhibitor

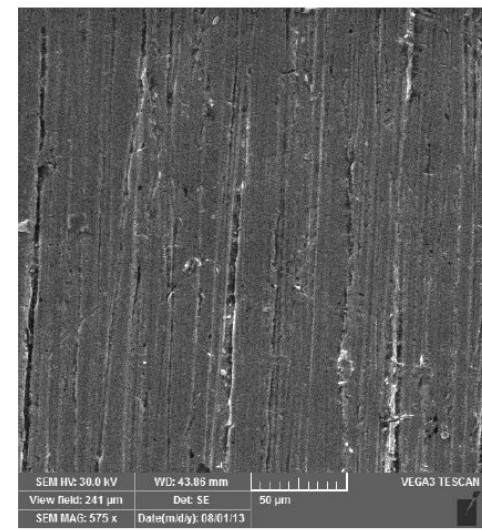

Figure 5c: with inhibitor 
Fig. 5a: polished metal surface before immersion, good surface properties; Fig. $5 \mathrm{~b}$ demonstrates strongly damaged metal surface in the absence of the inhibitor formulation, due to dissolution of the metal in the bulk of the environment. The surface is highly porous with large uneven oxides formed over it. Nevertheless, from Fig. 5c the dissolution rate of carbon steel suppressed and smoother surface was observed due to formation of a protective film onto the metal surface when compared to the treated one without the inhibitor in well water. This phenomenon showed that the presence of a protective film can protect the carbon steel surface from corrosion efficiently.

\section{Atomic force microscopy}

AFM is a powerful technique to probe the surface morphology at nano-to microscale and has developed into a new option to study the influence of inhibitor formulations on the generation and progress of the corrosion at the metal/solution interface. The three dimensional AFM morphologies for polished carbon steel surface immersed in without and with an inhibitor formulation are shown in Fig. 6.

Table 7. AFM data for carbon steel immersed in without and with inhibitor systems.

\begin{tabular}{|c|c|c|c|}
\hline Samples & $\begin{array}{c}\text { RMS }\left(\mathbf{R}_{\mathbf{q}}\right) \\
\text { Roughness }(\mathbf{n m})\end{array}$ & $\begin{array}{c}\text { Average }\left(\mathbf{R}_{\mathbf{a}}\right) \\
\text { Roughness }(\mathbf{n m})\end{array}$ & $\begin{array}{c}\text { Maximum Peak - to - } \\
\text { valley Height (nm) }\end{array}$ \\
\hline $\begin{array}{c}\text { Without inhibitor } \\
\text { system (blank) }\end{array}$ & 310.0 & 235.7 & 914 \\
\hline $\begin{array}{c}\text { Polished carbon steel } \\
\text { (Reference) }\end{array}$ & 168.5 & 133.1 & 480.0 \\
\hline With inhibitor system & 110.2 & 88.8 & 300.3 \\
\hline
\end{tabular}

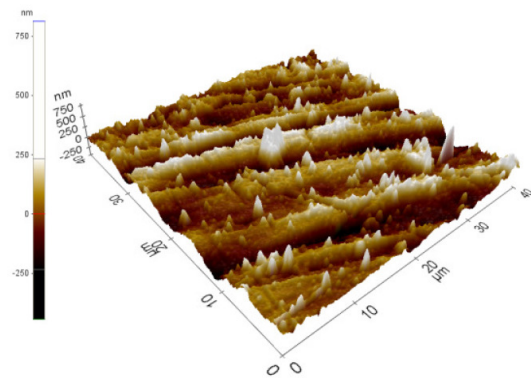

(a)
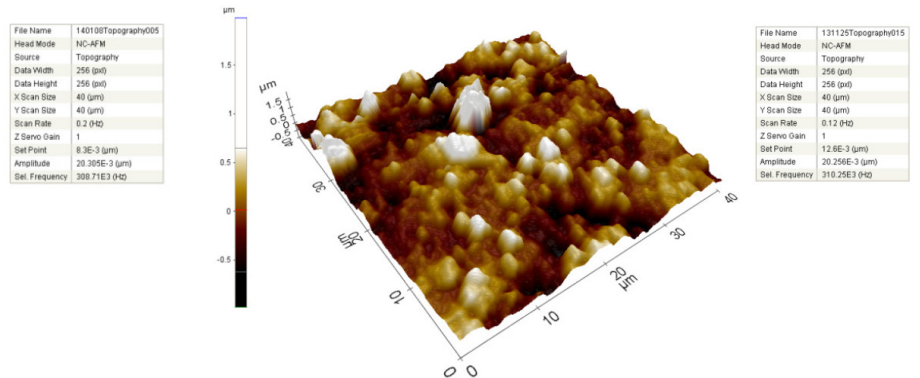

(b)

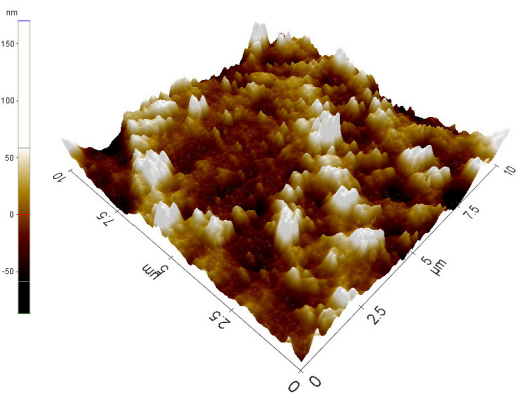

(c)

Figure 6. Polished carbon steel surface (a); without inhibitor (blank) (b); and with

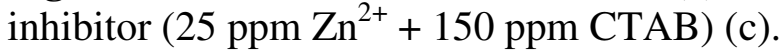


The root mean square (rms) roughness measurements were carried out for polished carbon steel, uninhibited and inhibited carbon steel surface. The vertical lines in the polished carbon steel sample are due to the fine scratches obtained during the polishing process [44]. The rms roughness and maximum peak - to peak height data's suggest the carbon steel surface immersed in well water has a greater surface roughness than the inhibited metal surface (Table 7). The presence of inhibitor formulation in well water significantly reduces to $88.8 \mathrm{~nm}$, when compared with $235.7 \mathrm{~nm}$ and $133.1 \mathrm{~nm}$ of carbon steel surface immersed in well water and polished carbon steel surface. These parameters confirm that the surface appears smoother; the smoothness of the surface is due to the formation of a protective film of $\left(\mathrm{CTAB}+\mathrm{Zn}^{2+}\right)$ on the metal surface thereby inhibiting the corrosion of carbon steel.

\section{Conclusions}

The following conclusions are drawn from the present study:

1. The formulation $\left(\mathrm{Zn}^{2+}+\mathrm{CTAB}\right)$ was found to be a good inhibitor for carbon steel in well water.

2. Inhibition efficiency (91\%) obtained from weight loss data and synergism parameter is comparable with those obtained from polarization and AC impedance measurements and they are in good agreement.

3. Tafel curves revealed that the formulation is an anodic inhibitor.

4. FTIR spectra show that the protective film consists of $\mathrm{Fe}^{2+}-\mathrm{CTAB}$ complex and $\mathrm{Zn}(\mathrm{OH})_{2}$ and oxides of Fe. Nyquist curves indicate that a protective film is formed onto the metal surface.

5. SEM and AFM studies support that the inhibitor molecules form a good protective film onto the metal surface.

\section{References}

1. Choi SY, Yoo KY, Lee JB, et al. Appl Therm Eng. 2010;30:2067-2072.

2. Ghafghazi S, Sowlati T, Sokhansanj. S, et al. Appl Energy. 2010;87:11341140.

3. Harvey D. A Handbook on Low Energy Buildings and District Energy Systems: Fundamentals, Techniques and Examples. London: Earthscan Publications; 2006.

4. Skagestad B, Mildenstein P. District Heating and Cooling Connection Handbook. IEA District Heating and Cooling; 1999.

5. Cohen M. J Electrochem Soc. 1946;89:11-13.

6. Eliseev K. District Heating System in Finland and Russia. Mikkeli University of Applied Sciences; 2011.

7. Galliano, Landolt FD. Prog Org Coat. 2002;44:217-225.

8. Lin B, Lu J, Kong G. Surf Coat Technol. 2008;202:1831-1838.

9. Kim JG, Kim YW. Corros Sci. 2001;43:2011-2021.

10. El-Etre AY, Abdallah M. Corros Sci. 2000;42:731-738.

11. Rezenfeld IL. Corrosion Inhibitors. New York: McGraw-Hill; 1981. 
12. Boffardi BP. Metals Handbook: Corrosion. 9th ed. Vol. 13. OH: American Society for Metals, Metals Park; 1987.

13. Ali MR, Mustafa CM, Habib M. J Sci Res. 2009;1:82-91.

14. Badawi AM, Hegazy MA, El-Sawy AA, et al. Mater Chem Phys. 2010;124:458-465.

15. Bastidas JM, Pinilla P, Polo JL, et al. Corros Sci. 2003;45:427-449.

16. Stipnisek-Lisac E, Gazivoda A, Madzarac M. Electrochim Acta. 2002;47:4189-4194.

17. Sahin M, Bilgic S, Yilmaz H. Appl Surf Sci. 2002;195:1-7.

18. Sing DN, Dey AK. Corrosion. 1993;49:594.

19. Banerjee G, Mahotra SN. Corrosion. 1992;48:10.

20. Arab ST, Noor EA. Corrosion. 1993;49:122.

21. Raspi LA. Nickel Corros. 1993;49:821.

22. Chen Y, Wang Y, Zhang G. Daily Chem Ind. 1986;2:56.

23. Shi L, Song H. Daily Chem Ind. 1987;1:9.

24. Wang XM, Yang HY, Wang FH. Corros Sci. 2011;53:113.

25. Wang XM, Yang HY, Wang FH. Corros Sci. 2010;52:1268.

26. Qiu LG, Wu Y, Wang YM, et al. Corros Sci. 2008;50:576.

27. Saleh MM, Atia AA. J Appl Electrochem. 2006;36:899.

28. Hegazy MA. Corros Sci. 2009;51:2610.

29. Huang W, Zhao J. Col Surf A. 2006;278:246.

30. Dumas Ph, Butffakhreddine B, Am C, et al. Europhys Lett. 1993;22:717.

31. Bennett JM, Jahannir J, Podlesny JC, et al. Appl Opt. 1995;43:213.

32. Duparre A, Kaiser N, Truckenbrodi H, et al. Proceedings of SPIE. 1993;1995:181.

33. Amra C, Deumie C, Torricini D, et al. Proceedings of SPIE. 1994;2253:614.

34. Aramaki K, Hackerman N. J Electrochem Soc. 1969;116:568.

35. Larabi L, Harek Y, Traisnel M, et al. J Appl Electrochem. 2004;34:833.

36. Touhami F, Aouniti A, Abed Y, et al. Corros Sci. 2000;42:929.

37. Jüttner K. Electrochem Acta. 1990;35:1501.

38. Muralidharam S, Phani KLN, Pitchumani S, et al. J Electrochem Soc. 1995;142:1478.

39. Popova A, Sokolova E, Raicheva S, et al. Corros Sci. 2003;45:33.

40. Selvi ST, Raman V, Rajendran N. J Appl Electrochem. 2003;33:1175.

41. Thangavelu C, Patric Raymond P, Rajendran S, et al. Asian J Research Chem. 2011;4:402.

42. Thangavelu C, Umarani M, Sekar M, et al. RASAYAN J Chem. 2011;4:245.

43. Thangavelu C, Patric Raymond P, Rajendran S, et al. Asian J Research Chem. 2011;4:1033.

44. Kleber C, Hilfrich U, Schreiner M. Appl Surf Sci. 2007;253:3712. 